\title{
Narrativas contemporâneas: significado, diversidade e contexto*
}

\section{Contemporary narratives: meaning, diversity and context}

\author{
Sandra Maria Galheigo ${ }^{1}$
}

GALHEIGO S. M. Narrativas contemporâneas: significado, diversidade e contexto. Rev. Ter. Ocup. Univ. São Paulo, v. 20, n. 1, p. 8-12, jan./abr. 2009.

RESUMO: Este ensaio se propõe a discutir o lugar da narrativa no âmbito da Terapia Ocupacional contemporânea e o que faz dela um tema-síntese de saberes e práticas que revelam uma determinada concepção de mundo, de ser e de terapia. Confrontando as perspectivas técnico-científicas com as perspectivas críticas contemporâneas, o texto apresenta cinco marcadores que indicam as polaridades e tensões dessas duas perspectivas. São elas: fato e valor; validação e incerteza; unicidade e multiplicidade da terapia ocupacional; universalismo e relativismo; neutralidade e poder; e, atividade enquanto recurso e atividade enquanto práxis social e manifestação cultural.

DESCRITORES: Narração. Terapia ocupacional/tendências.

\footnotetext{
* Texto adaptado da Conferência de Abertura do IX Congresso Brasileiro de Terapia Ocupacional, de 27 a 30 de setembro de 2005, Recife, PE.

1. Professora doutora, docente do Departamento de Fisioterapia, Fonoaudiologia e Terapia Ocupacional da Faculdade de Medicina da USP.

Endereço para correspondência: Centro de Docência e Pesquisa em Terapia Ocupacional da FMUSP, Rua Cipotânea, 51 Cidade Universitária, 05508-900, São Paulo-SP.
} 
O que é narrar? Narrar é: "expor, contar, relatar; referir, dizer; pôr em memória; registrar; historiar". Narrativa é também, segundo o Aurélio (2005), "a maneira de narrar; conto, história; exposição escrita ou oral de um fato; narração". Assim, associamos narrativa com o contar histórias, mas que podem acontecer de formas diferentes, seja usando a narrativa oral, a escrita, a imagética, a audiovisual.

"O que faz desse tema - narrativas contemporâneas - um tema-síntese tão próprio dos nossos tempos?"

Em busca de respostas, podemos estabelecer, como primeiro marcador, a tensão entre fato e valor. Sem dúvida, o narrador fala de fatos, eventos e experiências. Só que ele fala na linguagem dos contos e das histórias, isto é, ele fala não a partir do, ou rumo ao, fato em si mas, conta algo pelo valor e pelo significado que a ele atribui. Assim, ele escolhe qual história contar, por qual caminho seguir, que significado destacar. Objetividade, mensuração e prova não são requisitos de uma narrativa. Mas, a subjetividade, a significação e a contextualização do cenário o são.

Podemos assim dizer que as narrativas estão para as perspectivas críticas contemporâneas da terapia ocupacional assim como os testes e as medidas estão para as perspectivas técnico-cientificas. Assim, os tempos narrativos surgem da crise do paradigma que afirmava que o essencial para o cuidar de alguém estava no mensurar, avaliar, medir e provar seus infortúnios e, a partir do controle do detalhe, traçar-lhe objetivos e métodos de intervenção.

Entretanto, o conhecimento de informações e dados isolados tem se mostrado insuficiente para lidar com a complexidade da condição humana. De tal modo, os tempos contemporâneos estão deslocando a ação do terapeuta ocupacional do mundo biológico da doença e da disfunção para o mundo humano dos motivos, valores e crenças isto é, o mundo do significado e do sentido. O essencial se localiza na disponibilidade da escuta das necessidades e desejos - isto é, a busca de entender e interpretar histórias individuais e coletivas e construir, em conjunto, desfechos possíveis. Indo além, podemos afirmar que o contar e o escutar histórias precisa de espaço continente, de ambiente acolhedor e de intermediário facilitador. Por outro lado, podemos dizer que seu acontecimento possibilita o acionamento e construção de redes de sociabilidade e suporte e, de espaços de negociação cultural.

O segundo marcador que norteia a resposta está na tensão entre validação e incerteza. A desconfiança permanente dirigida às formulações subjetivas, assim como às pesquisas qualitativas, reside na impossibilidade de sua validação estatística. Validar algo é atribuir algum grau de certeza e assim dar validade e tornar válido, e a partir de então, tornar legítimo ou legal. Testes e medidas podem ser validados. Narrativas e discursos subjetivos, não.

Podemos assim dizer que a incerteza está para os tempos contemporâneos assim como a validação estava para seus tempos técnico-cientificos. A complexidade das questões contemporâneas deslocou a pergunta do "Como validar?" para a questão "É necessário e suficiente validar?". Afinal, as questões contemporâneas se recusam a serem reduzidas a uma única dimensão de análise e os problemas a serem circunscritos às suas partes simples. Portanto, nos tempos contemporâneos, a validação e a busca da certeza estão perdendo seu lugar para a cautelosa admissão da incerteza; isto é, o medo do confronto dando lugar à valorização do contraditório que emerge nos contextos complexos e, também, nas narrativas.

Continuando a pergunta:

"O que faz desse tema - narrativas contemporâneas um tema-síntese tão próprio dos nossos tempos?"

é possível pensar num terceiro marcador - a tensão entre a unicidade e a multiplicidade na terapia ocupacional.

A busca de certezas tem feito terapeutas ocupacionais, principalmente nos países do norte, a criarem modelos universais que tentem dar conta dos diferentes papéis e demandas atribuídos aos terapeutas ocupacionais. Tal movimento se dá, embora não necessariamente nesta ordem: (a) pela demanda de validação de seus atos pelos sistemas de saúde; (b) por uma busca de afirmação de sua identidade a partir de um modelo único que garanta a consistência de suas ações; (c) e pela ausência de diálogo com a diversidade dos campos de ação e dos domínios de conhecimento pelos quais pode vir a transitar a terapia ocupacional.

O caminho do modelo único, entretanto, é o oposto do que temos traçado. Olhando os resumos de eventos científicos de terapia ocupacional como a produção do conhecimento recente nos periódicos de terapia ocupacional no Brasil, constatamos uma multiplicidade de campos, de olhares, de fundamentos e de metodologias de ação. Percebemos que a ação da terapia ocupacional no Brasil está buscando consonância com a diversidade das questões trazidas pelos campos de prática. Está ficando cada vez mais atenta às demandas das populações e dos sujeitos. Está integrandose aos discursos e norteadores teórico-metodológicos de cada campo em particular. Mesmo não sendo muitos, temos práticas variadas e, o que é reconfortante, estamos ficando à vontade com a diversidade.

Falar, portanto, em narrativas contemporâneas é tocar na questão da multiplicidade das ações da terapia ocupacional no Brasil. Assim sendo, podemos afirmar que a pergunta "Que narrativas as terapias ocupacionais têm a contar?" está para os tempos contemporâneos como a 
pergunta "A terapia ocupacional é uma ciência?" estava para seus tempos técnico-cientificos.

O quarto marcador que busca responder a pergunta inicial é a tensão entre universalismo e relativismo. As narrativas têm por pressuposto a manifestação da diversidade. Cada sujeito tem sua história e cada história seu contexto. Assim, as narrativas possibilitam justamente a manifestação da pluralidade dos modos de vida; enfim, a manifestação da diversidade.

As mudanças rápidas, abrangentes e contínuas que vêm acontecendo na sociedade contemporânea têm levado ao chamado "deslocamento", já que está sendo perdido o centro, ou melhor, um princípio articulador em torno do qual as identidades vêm a se constituir.

A "identidade mestra" da classe social vem enfraquecendo e vêm surgindo novas identidades, que são constituídas a partir de outros referenciais (étnicos, culturais, de gênero, geracionais, etc.). Como conseqüência, a identidade vai mudando na medida em que o sujeito é confrontado ou representado.

Antes a identidade era vista como automática. Falávamos de um indivíduo bio-psico-social, que era construído mentalmente a partir de alguns universais que definiam sua constituição biológica e mental, e sua interação social. No cotidiano contemporâneo, admitimos não saber a priori quem é esse sujeito, já que a identidade pode tanto ganhar contornos como perder dimensões. Como diz Santos (2006), "Identidades são, pois, identificações em curso" (p. 135). Assim, a identidade é dinâmica, pode ser constantemente modificada já que ela é sempre construída socialmente.

Podemos assim dizer que o sujeito (sob o olhar da diversidade) está para os tempos contemporâneos como o indivíduo bio-psico-social (sob o olhar dos universais) estava para seus tempos técnico-cientificos.

E aí se coloca o quinto marcador, que flutua na tensão neutralidade e poder. Afinal, o que o indivíduo bio-psicosocial tem em comum com o sujeito contemporâneo é que ambos têm suas condições de existência, produção e criação, estabelecidas no diálogo e resistência às relações de poder que são intrínsecas às relações sociais e aos modos de produção. A diferença reside nos graus de alienação e consciência crítica que, respectivamente, envolvem as duas perspectivas. O paradigma que sustenta a figura do indivíduo bio-psico-social, o faz de forma alienada, na medida em que pensa suas condições a partir de uma pretensa neutralidade da ação do terapeuta. Já a consciência crítica com que se pensa o sujeito contemporâneo parte da perspectiva de que suas condições são fruto de uma construção histórica e política. As narrativas contemporâneas, portanto, tendem a ser refletidas em referência ao contexto social e histórico. Consciente disso, o sujeito contemporâneo apodera-se de sua história e pode buscar a emancipação e a transformação social.

De tal modo, os tempos contemporâneos estão deslocando a ação do terapeuta ocupacional do mundo atomizado do indivíduo para o mundo humano das organizações e dos conflitos - isto é, o mundo da práxis histórica e social.

O sexto (e último marcador) é relativo à relação que nós, terapeutas ocupacionais, estabelecemos com a atividade humana. Manifesta-se, então uma tensão entre duas perspectivas: a atividade enquanto recurso e a atividade enquanto práxis social e manifestação cultural.

O terapeuta ocupacional, em suas origens, foi apresentado à atividade humana em sua versão instrumental. A atividade era (e ainda é) vista exclusivamente como seu recurso, seu meio de trabalho. Por muitas vezes, este fato tem servido como definidor de uma identidade, embutido na frase - "O terapeuta ocupacional é aquele que utiliza a atividade como recurso terapêutico".

Precisamos, portanto, transcender da visão mecanicista do "uso da atividade" para entendê-la em sua forma plena - como práxis social e política e, como manifestação cultural. O que as narrativas contemporâneas podem trazer de substantivo para o terapeuta ocupacional é a possibilidade de ele passar a olhar as atividades como narrativas humanas. Narrativas, não apenas contemporâneas, mas que têm estado presentes em todos os tempos humanos, em toda sua diversidade, em todas as dimensões, em diferentes contextos.

Narrativas humanas. Projetos repletos de sentido.

Das cavernas às galerias de arte.

Do cotidiano dos campos aos das cidades.

Do maculelê ao hip-hop.

Das festas juninas ao Cirio de Nazaré.

Da amarelinha ao esconde-esconde.

Da feijoada a paella.

Da renda de bilro à tecelagem.

Do caminhão de madeira às pontes de concreto $\mathrm{e}$ nuvem.

Dos quebra-cabeças aos mosaicos.

Dos vasos chineses à cerâmica marajoara.

Do teatro de marionetes ao teatro espontâneo.

Do crochê ao macramé.

Do samba de roda ao Michael Nyman.

Do conselho tribal ao Movimento dos Sem-Terra.

De Rodin a Miró. De Pollock a Basquiat.

Dos cavalos de Octávio Ignácio às mandalas de 
Fernando Diniz.

Narrativas Humanas em seus Inumeráveis Estados do Ser.

Cores, flores, dores, amores e vestidos ao vento.
Veleiros, bonecas, canecas e mantos.

Narrativas Humanas.

De Frida Khalo e Arthur Bispo do Rosário.
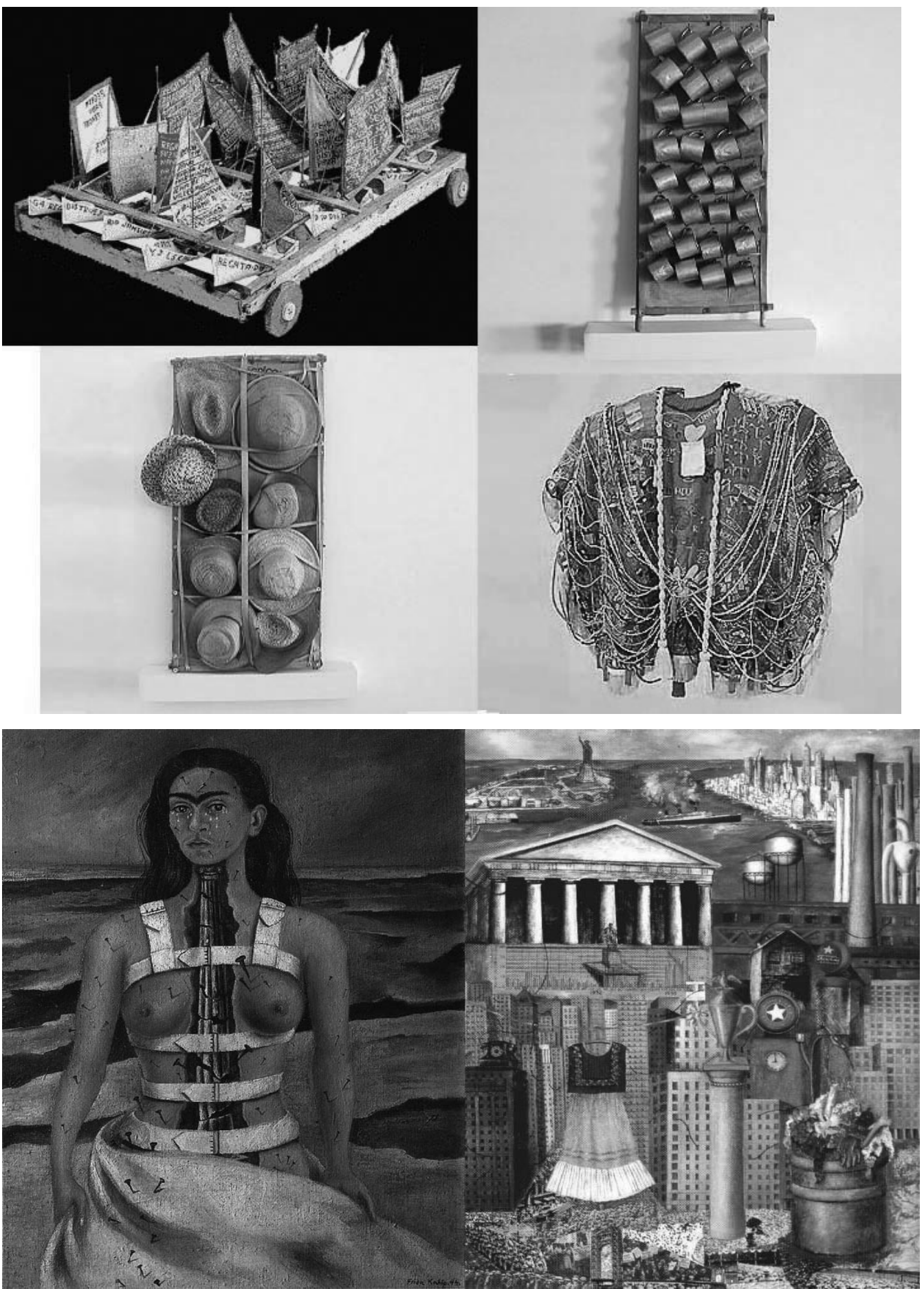
GALHEIGO S. M. Narrativas contemporâneas. Rev. Ter. Ocup. Univ. São Paulo, v. 20, n. 1, p. 8-12, jan./abr. 2009.

GALHEIGO S. M. Contemporary narratives: meaning, diversity and context. Rev. Ter. Ocup. Univ. São Paulo, v. 20, n. 1, p. 8-12, jan./abr. 2009.

\begin{abstract}
This essay intends to discuss the place of narrative in the domain of the contemporary Occupational Therapy and what makes it a synthesis-theme of knowledge and practice which reveals a certain view on the world, on being and therapy. Confronting the technical and scientific perspectives with the critical ones, the text presents five markers which indicate polarities and tensions between both perspectives. They are: fact and value; validation and uncertainty; unity and multiplicity of occupational therapy; universalism and relativism; neutrality and power; and, activity as a resource and activity as social praxis and cultural manifestation.
\end{abstract}

KEY WORDS: Narration. Occupational therapy/trends.

\title{
REFERÊNCIAS
}

FERREIRA, A. B. H. Novo dicionário Aurélio eletrônico. 2005. CD-Rom.

KHALO, F. Broken column. Disponível em: <http://www.uwm. edu/People/julietal/TheBrokenColumn44c.jpg>. Acesso em: 17 abr. 2009.

KHALO, F. My dress hangs here. Disponível em: $<$ http://www.1start-gallery.com/thumbnail/72084/1/My-Dress-Hangs-There.jpg>. Acesso em: 17 abr. 2009.

ROSÁRIO, A. B. Canecas. Disponível em: <http://www.proa. org/exhibiciones/pasadas/inconsciente/salas/id_bispo_10.html $>$. Acesso em: 17 abr. 2009.
ROSÁRIO, A. B. Manto de apresentação. Disponível em: $<$ http://www.proa.org/exhibiciones/pasadas/inconsciente/salas/ id_bispo_1.html>. Acesso em: 17 abr. 2009.

ROSÁRIO, A. B. Sem título. Disponível em: < http://www.proa. org/exhibiciones/pasadas/inconsciente/salas/id_bispo_14.html>. Acesso em: 17 abr. 2009.

ROSÁRIO, A. B. Vinte e um veleiros. Disponível em: $<$ http://1.bp.blogspot.com/_Xz_boM2LY-8/SErlLSQz8JI/ AAAAAAAABeI/pj3jewNm_vk/s1600-h/21veleiros_g.gif>. Acesso em: 17 abr. 2009

SANTOS, B. S. Pela mão de Alice: o social e o político na pósmodernidade. São Paulo: Cortez Editora, 2006. 